\title{
Mean T Wave Axis
}

National Cancer Institute

\section{Source}

National Cancer Institute. Mean T Wave Axis. NCI Thesaurus. Code C62146.

The mean (average) direction (range -180 degrees to 180 degrees) of the electrical potential generated from ventricular repolarization in a particular plane (usually the frontal plane). 